\title{
Welcome to the December 2014 Issue of the IJTMB
}

\author{
Antony Porcino, PhD, HSI \\ Executive Editor, IJTMB
}

CARE Program, Pediatrics, Faculty of Medicine \& Dentistry, University of Alberta, Edmonton, AB, Canada

This issue of the IJTMB brings a spectrum of research to readers.

In the Research Section, you will find a listing of the abstracts of research project posters presented at the recent American Massage Therapy Association 2014 National Convention. These abstracts were peer-reviewed by a committee of Massage Therapy Foundation volunteers. The nine posters cover topics from case reports for several different conditions to full research trials. The IJTMB is pleased to be able to showcase these research efforts.

The three Practice Section articles show some of the diversity of research that can fall within its domain. We have two case reports. One explores zen shiatsu for stress reduction in a child with autism spectrum disorder, which links nicely with the article by Silva et al. on qi gong massage for tactile impairment in young children with autism from last December's issue (http://www.ijtmb.org/index.php/ijtmb/article/ view/227). The second is a case report of treatment for thoracic outlet syndrome. A commonly discussed condition that many therapeutic massage providers treat, it seems to be lacking in recent research. If you would like either of these conditions/populations discussed as part of "Trigger Points", do contact the Practice and Education Section Editors with your requests - their contact information is in this issue's Practice Section Editorial on the current "Trigger Point" topic.
The final article takes us to the first research exploration of the practice of consent in therapeutic massage. It asks us to re-examine our own relationship to the consent process and what it means in our practice, as well as what our expectations should be around giving patients an engaged consent process that is appropriate to the treatment context. As well, it is a good reminder that possible solutions to some of the complex issues in therapeutic massage practice, education, and research may already be answered - or the needed process or discussion more advanced - in our sister professions such as nursing or, in this case, physiotherapy.

Enjoy this December's issue of the IJTMB.

\section{COPYRIGHT}

Published under the CreativeCommons AttributionNonCommercial-NoDerivs 3.0 License.

Corresponding author: Antony J. Porcino, BSc, PhD, HSI, CARE Program, 8B19, Unit 8B Edmonton General Hospital, 11111 Jasper Avenue, University of Alberta, Edmonton, AB T5K 0L4

E-mail: eeitjmb@gmail.com 